$12-2010$

\title{
The Intensivist
}

\section{Ed Marchan}

Jack Jallo

Fred Rincon

Matthew Vibbert

Follow this and additional works at: https://jdc.jefferson.edu/jhnj

\section{Let us know how access to this document benefits you}

\section{Recommended Citation}

Marchan, Ed; Jallo, Jack; Rincon, Fred; and Vibbert, Matthew (2010) "The Intensivist," JHN Journal: Vol. 5 : Iss. 2 , Article 4.

DOI: https://doi.org/10.29046/JHNJ.005.2.004

Available at: https://jdc.jefferson.edu/jhnj/vol5/iss2/4

This Article is brought to you for free and open access by the Jefferson Digital Commons. The Jefferson Digital Commons is a service of Thomas Jefferson University's Center for Teaching and Learning (CTL). The Commons is a showcase for Jefferson books and journals, peer-reviewed scholarly publications, unique historical collections from the University archives, and teaching tools. The Jefferson Digital Commons allows researchers and interested readers anywhere in the world to learn about and keep up to date with Jefferson scholarship. This article has been accepted for inclusion in JHN Journal by an authorized administrator of the Jefferson Digital Commons. For more information, please contact: JeffersonDigitalCommons@jefferson.edu. 


\title{
The Intensivist
}

\author{
Edward M. Marchan, MD, Jack I. Jallo, MD, ${ }^{2}$ Fred Rincon MD, ${ }^{1,2}$ \\ Matthew Vibbert, MD ${ }^{1,2}$
}

${ }^{1}$ Department of Neurology and ${ }^{2}$ Department of Neurological Surgery, Thomas Jefferson University, Philadelphia, PA

\section{Background}

The intensivist is the primary care physician of the ICU. Critically ill patients often have multiple acute and chronic illnesses requiring the careful integration of information and recommendations from multiple consultants. In addition to acting as a physician, intensivists commonly are administrators of an ICU. In 1992, the Society of Critical Care Medicine ${ }^{1}$ published its guidelines for the definition of an intensivist and the intensivist's role in an ICU (Table 1). Likewise, the Leapfrog consortium ${ }^{2}$ defines an intensivist as:

1. A board-certified physician who is certified in critical care medicine, or

2. Board-certified emergency medicine physicians who have completed an Accreditation Council for Graduate Medical Education accredited critical care fellowship, or

3. Physicians board certified in internal medicine, anesthesiology, pediatrics, or surgery who completed training before availability of critical care fellowship training and have provided $>6$ wks of full-time ICU care annually since 1987

3) skill sets involved. ${ }^{1}$

a. Rapidly identify, assess, and resuscitate a critically ill patient while being able to swiftly provide treatment of cardiogenic, neurogenic, and hypovolemic shock using some of the most modern approaches.

b. Integrate the information provided by consultants who see the patients in the ICU to come up with an appropriate treatment plan that incorporates these recommendations.

c. Able to continuously keep up with and assimilate new findings in the published medical literature.

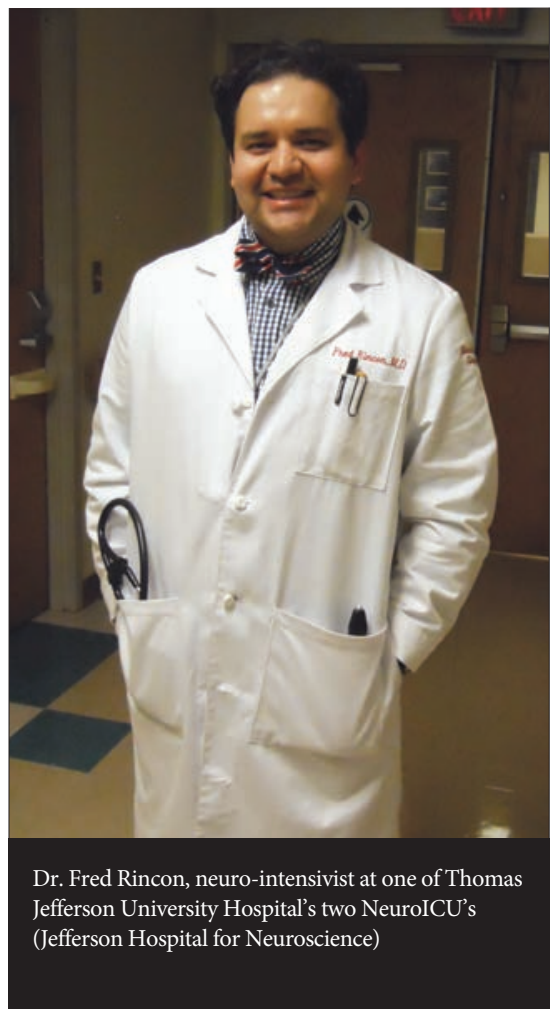

\section{Table 1: Society of Critical Care Medicine's definition of intensivist}

\section{Diagnoses, manages, and delivers the care of critically ill patients.}

Has the medical training and skills to manage multiple heath problems, including but not limited to:

\section{1. $\quad$ Cardiovascular: shock, myocardial infarction, cardiac failure, arrhythmias}

2. Respiratory: prevention and treatment of pneumonia, respiratory failure, acute respiratory distress syndrome, chest trauma, smoke inhalation, and burns

3. Neurologic: stroke, traumatic brain injury, intracranial hypertension, seizures, brain death evaluation

4. Renal: insufficiency or failure, electrolyte and acid base disorders, rhabdomyolysis

5. Endocrine disorders: adrenal insufficiency, diabetic emergencies, thyroid storm

6. Gastrointestinal: pancreatitis, gastrointestinal bleeding, hepatic failure

7. Pharmacologic emergencies: overdose, drug reactions, poison

8. Hematologic: anemia, coagulation disorders, thrombotic disorders

9. Infectious disease: treatment of multiple infections and recognition of and treatment of sepsis

10. Nutritional: prevention, recognition, and treatment of malnutrition

Able to manage or perform certain unit-specific procedures, including but not limited to:

1. Endotracheal intubation and mechanical ventilation

2. Placement of intravascular catheters, including central venous catheters, pulmonary artery catheters, dialysis catheters, arterial catheters

3. Cardiac pacing device insertion and management

4. Tube thoracostomy 
d. Able to holistically understand the financial constraints within every health system, and emphasize the importance of efficiency and limitation of resources while maintaining quality care.

4) Manages directly the day to day care of the rather sick in extremis patient but also acts as the administrator of the ICU.

\section{Evidence Based Medicine Supporting The Role of the Intensivist}

A. Studies have been performed highlighting that critically ill patients should be cared for by an intensivist to optimize patient care and minimize morbidity and mortality.

\section{B. Li et al. ${ }^{5}$}

1. Compared outcomes in a ten-bed community ICU before and after hiring full-time intensivists.

2. After controlling for factors that predicted death (i.e., age, mental status, reason for ICU admission), severity of illness, and other co-morbidities, patients cared for by designated intensivists were more likely to survive their ICU stay and their subsequent hospital admission when compared with patients in the ICU cared for by their primary care physicians.

3. Patients who benefited the most were those in the intermediate range of severity of illness.

\section{Brown and Sullivan ${ }^{6}$}

1. Compared cohort of ICU patients before and after the introduction of an intensivist.

2. The first group comprised patients cared for by their primary attending physician and the second group comprised patients cared for by an intensivist in collaboration with the attending physician.

3. Addition of an intensivist was found to reduce ICU mortality by $52 \%(\mathrm{p}<0.01)$ and overall hospital mortality by $31.0 \%$ $(\mathrm{p}<0.01)$.

D. Hanson et al. ${ }^{7}$

1. Conducted a simultaneous cohort analysis that compared a group of ICU patients cared for by intensivists with a group of patients cared for by general surgeons.

2. Although there was no difference in ICU or hospital mortality, the group cared for by the ICU team spent less time in the ICU and had fewer complications.

\section{E. Pronovost et al. ${ }^{8}$}

1. Examined mortality and morbidity in patients hadmitted to an ICU after open abdominal aortic aneurysm surgery.

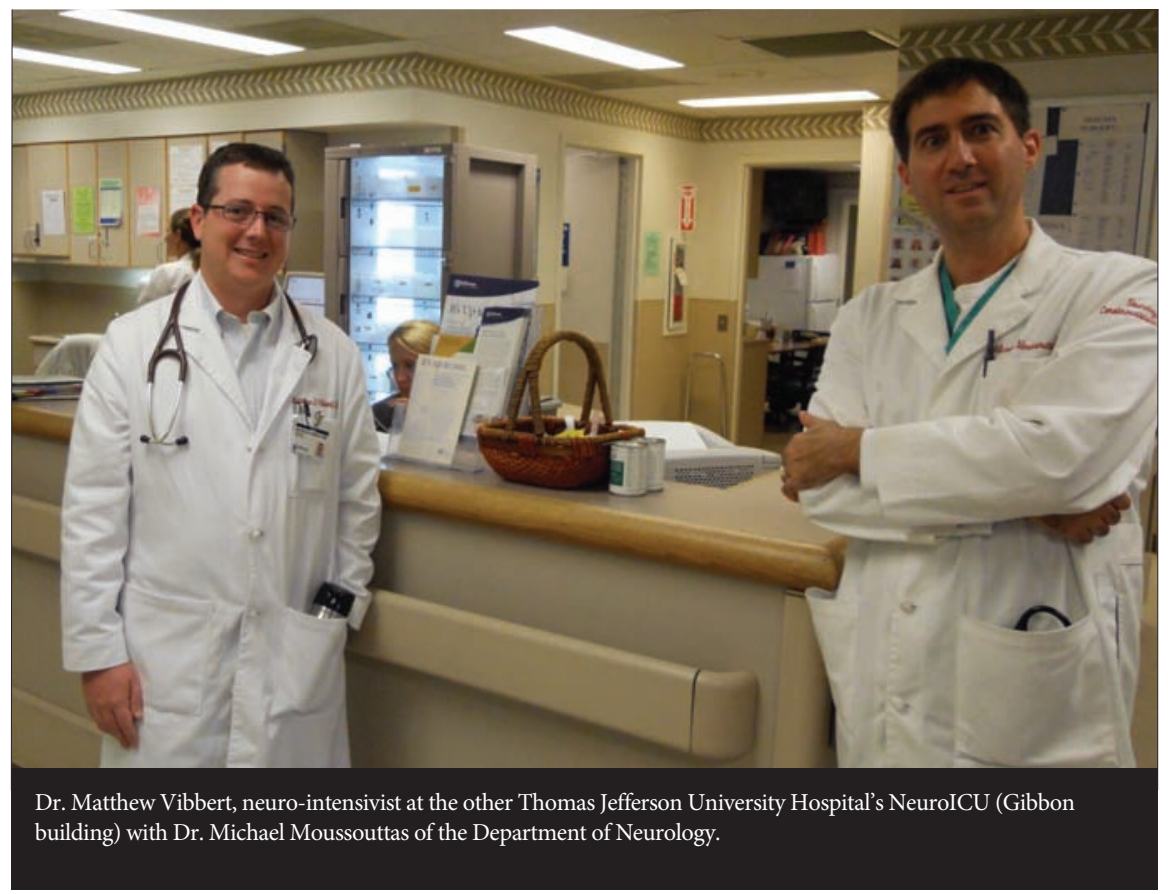

2. Results: Having daily rounds by an intensivist rather than care strictly provided by the attending surgeon and/or consultants reduced in-hospital mortality three-fold (odds ratio, 3.0; 95\% confidence interval, 2.1-4.3)

a. A meta-analysis was then performed by the same authors of 27 randomized and observational studies comparing outcomes and length of stay (LOS) in patients admitted to an ICU under low-intensity (no intensivist or elective intensivist consultation) vs. high-intensity (mandatory intensivist) consultation or closed ICU) paradigms.

b. The high-intensity models reduced hospital mortality (pooled relative risk, $0.71 ; 95 \% \mathrm{CI}, 0.62-0.82$ ) and ICU mortality (pooled relative risk 0.61; 95\% CI, $0.50-0.75)$ in the 17 studies that compared outcomes.

\section{Discussion}

A. The ICU physician staffing standard ${ }^{4}$ requires:

1. A dedicated intensivist be present during the daylight hours and have no other duties besides the ICU

2. During non-daylight hours, a dedicated intensivist should be able to respond to pages within 5 minutes and arrange for
Fundamental Critical Care Supportcertified nonphysician surrogate to be able to reach any covered patient within 5 mins.

B. Costs

1. High costs may hinder the potential of all ICUs to be headed by a dedicated intensivist due to:

a. Having to recur in paying higher salaries for specialized care.

b. Studies have been performed highlighting quite the contrary:

1. Patients cared for by intensivists had lower ICU costs when looking at specific markers for resource utilization.

2. Intensivist-led team had shorter ICU length of stay fewer days of mechanical ventilation fewer arterial blood gases required

i) shorter ICU length of stay

ii) fewer days of mechanical ventilation

iii) fewer arterial blood gases required

iv) fewer consultations with subspecialty physicians.

\section{Conclusions}

A. Intensivist holds a key position in the care of the ICU patient.

B. Intensivist not only improves outcomes but diminishes costs in the long run as nuances of care are minimized with more efficient care being provided. 
C. The published data, thus far, support the contention that trained intensivists are best suited to care for patients in an intensive care environment.

D. Critical care units that have designated intensivist led teams that round daily benefit from decreased mortality, morbidity, and length of stay.

\section{References}

Guidelines for the definition of an intensivist and the practice of critical care medicine: Guidelines Committee, Society of Critical Care Medicine. Crit Care Med. 1992; 20: 540-542.

1. http://www.leapfroggroup.org

2. Dorman T, Angood PB, Angus DC, et al: Guidelines for critical care medicine training and continuing medical education. Crit Care Med. 2004; 32:263-272.

3. Gutsche JT, Kohl BA. Who should care for intensive care unit patients? Crit Care Med. 2007 Feb;35(2 Suppl):S18-23.

4. Li TC, Phillips MC, Shaw L, et al: On-site physician staffing in a community hospital intensive care unit: Impact on test and procedure use and on patient outcome. JAMA 1984; 252:2023-2027.

5. Brown JJ, Sullivan G: Effect on ICU mortality of a full-time critical care specialist. Chest 1989; 96:127-129.

6. Hanson CW III, Deutschman CS, Anderson HL III, et al: Effects of an organized critical care service on outcomes and resource utilization: A cohort study. Crit Care Med. 1999; 27:270-274

7. Pronovost PJ, Jenckes MW, Dorman T, et al: Organizational characteristics of intensive care units related to outcomes of abdominal aortic surgery. JAMA 1999; 281:1310-1317.

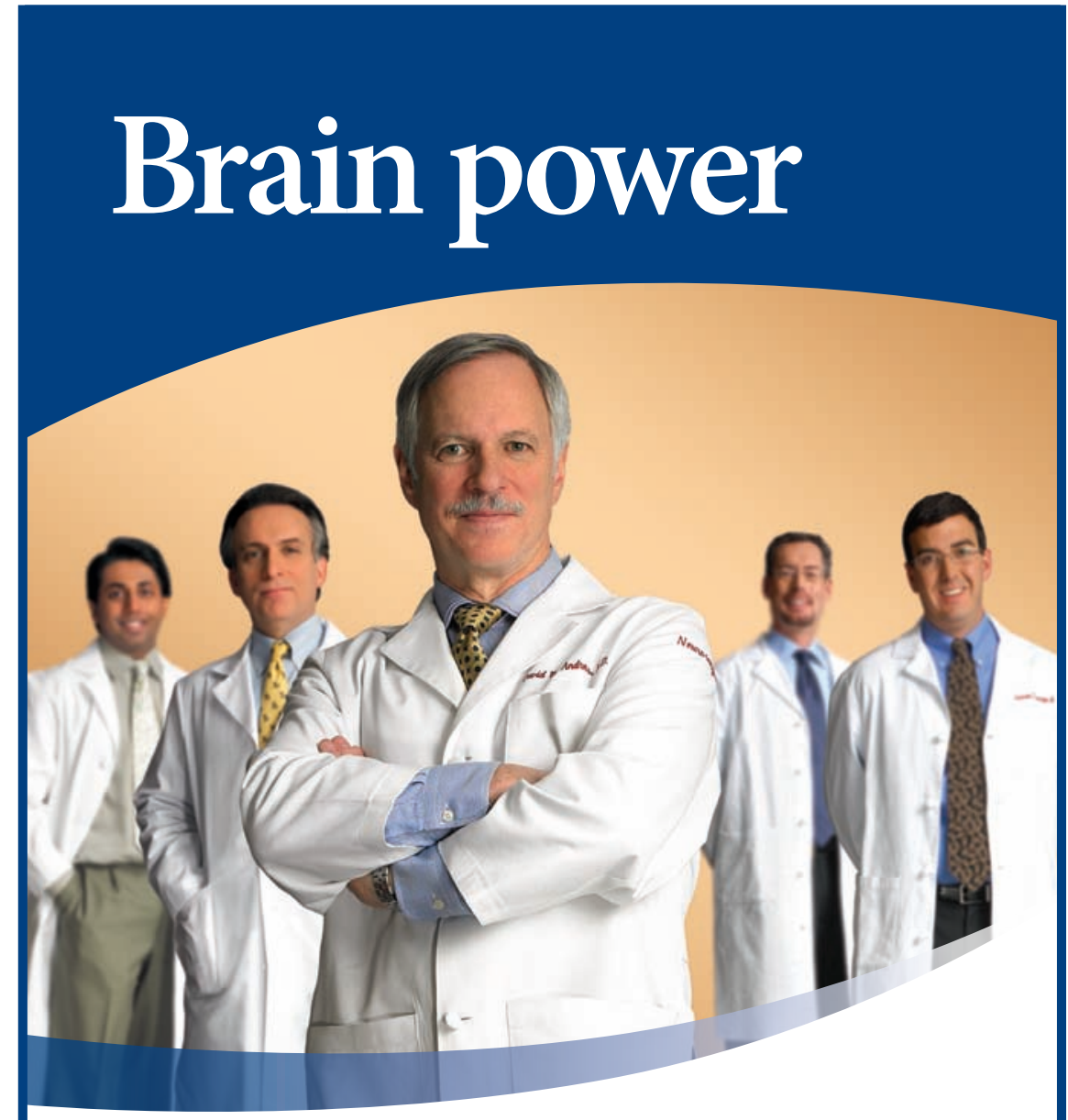

Jefferson neurosurgeons have helped to write the textbooks and set training standards referenced by other doctors around the world. No wonder our surgeons treat the largest combined volume of tumors, aneurysms and AVMs in the Philadelphia region.

The region's only hospital with an experienced, specialized staff dedicated to neuroscience.

Offices in Center City Philadelphia, Langhorne and Voorhees. Most insurance plans accepted, including Medicare.

\section{Jefferson.}

\section{Hospital for Neuroscience}

- Thomas Jefferson University Hospital

- Jefferson Hospital for Neuroscience

- Methodist Hospital 